\title{
«A melhor fruta que há no mundo»: o paradoxo do durião
}

\author{
Mário Berberan e Santos \\ Centro de Química-Física Molecular e Instituto de Bioengenharia e Biociências \\ Instituto Superior Técnico, Universidade de Lisboa, 1049-001 Lisboa \\ *berberan@tecnico.ulisboa.pt
}

The best fruit in the world»: the durian paradox - The durian, a fruit from Southeast Asia, has unique organoleptic characteristics: excellent taste and consistency, but a very unpleasant odour (for the uninitiated), which has limited its diffusion. Besides the description of the fruit and its properties, including the main compounds responsible for the smell, the history of its initial knowledge by the Europeans, including the Portuguese contribution, is discussed and clarified.

Ourião, fruto originário do sudeste asiático, tem características organoléticas únicas: um sabor e uma consistência excelentes, mas um odor muito desagradável (para os não iniciados), o que tem limitado a sua difusão. Para além da descrição do fruto e das suas propriedades, incluindo os principais compostos responsáveis pelo odor, apresenta-se e clarifica-se a história do seu conhecimento inicial pelos europeus, incluindo a contribuição portuguesa.

\section{Introdução}

O durião, «rei dos frutos», é um fruto paradoxal, pois tem um cheiro geralmente considerado fétido, mas um sabor e consistência deliciosos. É, provavelmente, um caso único nos vegetais crus comestíveis, mas encontramos o mesmo perfil organolético ambivalente em queijos que nos são familiares, cujo cheiro apenas se torna tolerável pelos sabor e consistência ótimos, por exemplo o Queijo da Serra. Há, certamente, em todos estes casos, um mecanismo de aprendizagem, em que a pessoa, perante um alimento que reconhece e cujo sabor memorizou, desvaloriza a advertência genérica desencadeada pelo sistema olfativo ou é, até, capaz de reconhecer a diferença subtil no odor. É um exemplo de gosto por habituação (acquired taste), processo bem traduzido pelo slogan devido a Fernando Pessoa, «primeiro estranha-se, depois entranha-se». De facto, nos alimentos e nas bebidas, há quase sempre concordância entre cheiro e paladar, e podemos muitas vezes «adivinhar» o sabor pelo cheiro. Este tem, com efeito, uma importância enorme no próprio paladar. Não é por acaso que, quando estamos muito constipados, a comida «não sabe a nada».

Também é interessante notar que toleramos muito melhor os maus cheiros próprios do que os alheios, donde se conclui, novamente, não ser a nossa perceção do odor apenas o resultado da composição química e concentração dos constituintes de um gás ou vapor.

Os «não iniciados» (a grande maioria) têm, por conseguinte, uma extrema repulsa pelo cheiro do durião, exacerbado em climas quentes, como são os do Sudeste Asiático (Malásia, Indonésia, Tailândia, entre outros países), onde é cultivado e apreciado. No metropolitano de Singapura, por exemplo, é proibida a entrada de duriões, Figura 1*, sob pena de expulsão.

Imagine-se o(a) leitor(a) em Lisboa, no pino do verão, num metropolitano a transbordar, levando, num mero saco de papel, um Queijo da Serra já encetado: abrir-se-ia uma

\footnotetext{
* Todas as fotografias a cores deste artigo foram tiradas pelo autor.
}

clareira à sua volta, e talvez fosse mesmo amavelmente convidado(a) a sair da carruagem na próxima estação...

Atualmente, a parte comestível do durião pode ser comprada embalada em vácuo (e, até, liofilizada), o que evita ao comprador embaraços e dissabores nos transportes.

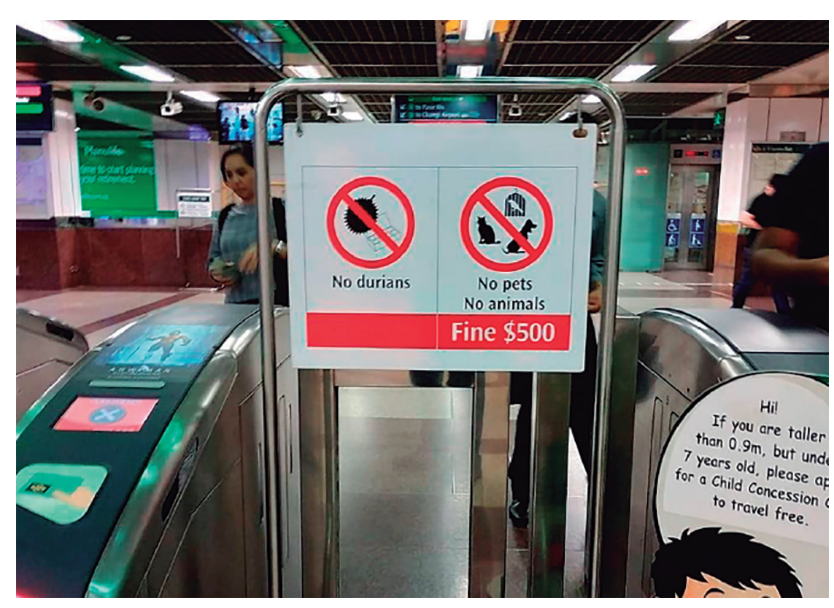

Figura 1 - Aviso no metropolitano (MRT) de Singapura. Quinhentos dólares de Singapura equivalem a cerca de 320 euros, no entanto, a multa aplica-se apenas aos animais. O transporte de duriões não é permitido, mas não há multa em dinheiro, apenas expulsão.

Ainda assim, nestes tempos de globalização, e de importação de frutos exóticos, poucos europeus já provaram ou ouviram sequer falar do durião. É o caso de Portugal, pese embora termos sido os primeiros a descobrir, a comer habitualmente e a louvar o fruto, como se descreve mais abaixo neste artigo. Foi uma memória asiática que se desvaneceu, certamente na sequência da perda de Malaca (1641). Atualmente, segundo as estatísticas oficiais, as importações anuais de durião pouco excedem as duas toneladas, o que corresponde, em média (uma vez que há sazonalidade na produção), a apenas cerca de dois duriões por dia (como comprovado pelo autor, em deslocação ao MARL). 
Na China, pelo contrário, onde também não se produz, o durião é muito popular, e a sua importação, em crescimento, atinge presentemente mais de 350.000 toneladas/ ano. Não admira, portanto, que encontremos o durião noutros pontos do planeta onde há comunidades chinesas significativas, Figura 2.

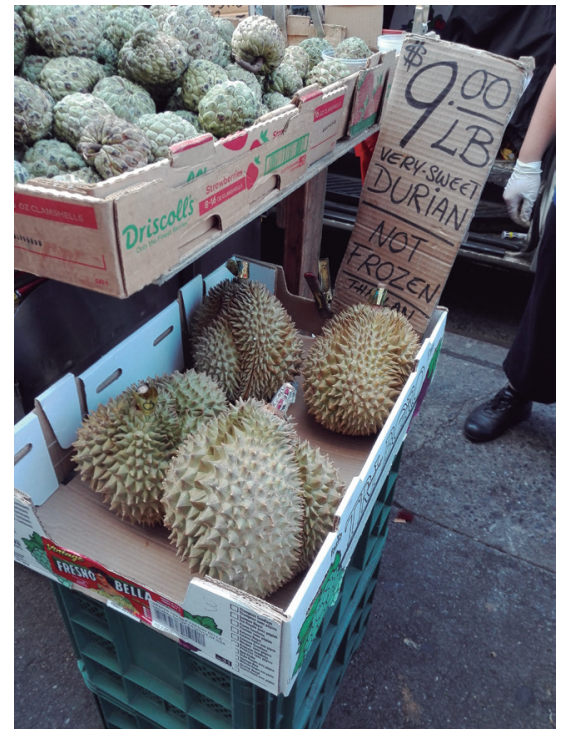

Figura 2 - Duriões importados da Tailândia (escrita “Thailan”), à venda na Chinatown de Nova Iorque (agosto de 2017). O fruto pesa de dois a cinco quilogramas. Note-se a informação: «Não congelado». Com efeito, uma grande parte do fruto exportado é-o sob a forma congelada.

\section{A descoberta do durião pelos europeus}

O durião é um fruto tradicional do sudeste asiático, inicialmente localizado na área correspondente a Bornéu, Malásia e Samatra, mas tendo-se depois expandido para regiões vizinhas, designadamente a Tailândia, presentemente o seu principal produtor para exportação.

Por ser assunto mal estudado e pior sistematizado, e ainda pela relevância do contributo português, frequentemente ignorado ou interpretado erradamente, apresenta-se de seguida uma cronologia comentada das primeiras referências ao durião por autores europeus ou dessa esfera cultural [1], tal como apurado por consulta dos trabalhos existentes sobre o assunto e das referências originais (mas sem reivindicação de completude), resumida no Quadro 1.

A origem das confusões e lacunas é, pelo menos, tripla: a) Datando do séc. XIX, com as menções do durião em duas obras britânicas ainda hoje de referência: o livro de viagens do naturalista Wallace, The Malay Archipelago (1869) [2] e o dicionário anglo-indiano Hobson-Jobson (1886) [3], este último com uma compilação significativa de referências (e.g. Conti, Castanheda, Barros e Orta) mas incompleta, tanto no número como, principalmente, no teor; b) uma extensa revisão bibliográfica de 1997 [4], que começa por uma descuidada resenha histórica, o que não é invulgar neste tipo de trabalhos.

A melhor seleção de títulos portugueses quinhentistas e seiscentistas sobre o durião, até hoje sem impacto internacional, deve-se a Sebastião Dalgado (entrada «Durião» no Glossário Luso-Asiático, Imprensa da Universidade, Coimbra, 1919), que cita quase todos os autores do
Quadro 1, com a importante e compreensível exceção de Tomé Pires, autor só redescoberto em 1937.

\section{4-1492: Nicolau Veneto}

A primeira notícia do durião que chegou à Europa e de que ficou registo é a do mercador e viajante veneziano Nicolò de' Conti (ca. 1395-1469), entre nós chamado Nicolau Veneto. Conti passou duas décadas e meia viajando pelo Oriente (1414-1439), onde conheceu a mulher, provavelmente cristã da Índia [5,6]. Voltou a casa, acompanhado de dois filhos (a mulher, bem como dois outros filhos, morreram de peste, no Cairo, já no regresso) [5]. Por ordem do Papa, e como penitência por uma conversão forçada ao islamismo, durante a viagem, faz, então, um relato oral das suas experiências inauditas, que é compilado em latim [6]. O texto circula em cópias manuscritas até 1492, ano em que é publicada uma edição impressa [6]. Faz-se uma tradução portuguesa logo em 1502 [5].

Na ilha de Samatra, onde viveu cerca de um ano, Conti descobre antropófagos temíveis [5,6], mas também o durião, em Samudera (Achém), reino no norte da ilha [1]:

«(..) há um fruto verde a que chamam Duriano [durianum, no original latino], do tamanho de um pepino [cohombro], no interior do qual se encontram cinco outros, do tamanho de laranjas, um pouco alongados, de sabor variado [desvairado sabor, varii saporis], como manteiga coalhada [nata]» (versão modernizada da tradução portuguesa).

A descrição não denota especial entusiasmo pelo fruto, cujo odor, tão característico, não é referido. Cucumeris, no texto latino, também pode significar melancia, o que é mais próximo da realidade, no que se refere ao tamanho e forma. A tradução italiana de 1550 [5], que agora refere um «sabor excelente» (eccellente sapore), sem dúvida incorporando informação posterior a Conti, usa precisamente anguria (melancia). Os «frutos» internos são, de facto, as sementes, cujo substancial revestimento carnudo (arilo) constitui a parte comestível.

\section{2-1515: Tomé Pires}

A singularidade e primazia do durião só é, contudo, reivindicada por Tomé Pires (ca. 1468-ca. 1540) [7], primeiro autor português a falar deste fruto. Pires, boticário e escrivão, viveu em Malaca durante quase três anos, logo após a sua conquista por Afonso de Albuquerque (1511). Na Suma Oriental (1512-1515), obra de grande importância e rigor, redescoberta apenas em 1937, como já se disse, escrita, em parte, precisamente em Malaca, afirma haver nos arrabaldes desta cidade:

«a fruta dos duriões, que é a melhor fruta que há no mundo»!

Pires assinala, ainda, a abundância dos «formosos e gostosos» duriões também na vizinha ilha de Samatra.

\section{2: Fernão Lopes de Castanheda}

O cronista Castanheda (1500-1559), que viveu dez anos em Goa, na História do Descobrimento e Conquista da Índia pelos Portugueses, ao tratar de Malaca (livro II, cap. CXIV, Coimbra, 1552), afirma: 
Quadro 1 - Primeiras referências ao durião por autores europeus e por um autor luso-asiático (omitem-se os autores referidos no texto que apenas repetem outros).

\begin{tabular}{|c|c|c|c|}
\hline data & autor & novidade & $\begin{array}{l}\text { Tipo de conhecimento } \\
\text { e local }\end{array}$ \\
\hline $\begin{array}{c}1444 \text { (manuscrito) } \\
1492 \text { (obra impressa) } \\
1502 \text { (tradução portu- } \\
\text { guesa) }\end{array}$ & Nicolau Veneto & $\begin{array}{l}\text { O Duriano, de «desvairado sabor», } \\
\text { existente em Samatra }\end{array}$ & $\begin{array}{l}\text { Conhecimento direto } \\
\text { (Samatra) }\end{array}$ \\
\hline 1512-15 & Tomé Pires & $\begin{array}{l}\text { «a melhor fruta que há no mundo», } \\
\text { existente em Malaca e Samatra }\end{array}$ & $\begin{array}{l}\text { Conhecimento direto } \\
\text { (Malaca) }\end{array}$ \\
\hline 1552 & Castanheda & $\begin{array}{l}\text { «sabor singular», pomo de Adão } \\
\text { (Malaca) }\end{array}$ & $\begin{array}{l}\text { Informações colhidas } \\
\text { em Goa }\end{array}$ \\
\hline 1553 & João de Barros & $\begin{array}{l}\text { «cousa muito estimada e gulosa», de } \\
\text { efeito afrodisíaco (Malaca) }\end{array}$ & $\begin{array}{l}\text { Informações recolhidas } \\
\text { em Portugal }\end{array}$ \\
\hline 1556 & P. ${ }^{e}$ Baltasar Dias & $\begin{array}{l}\text { «Um dos pomos mais suaves» (Ma- } \\
\text { laca) }\end{array}$ & $\begin{array}{l}\text { Conhecimento direto } \\
\text { (Malaca) }\end{array}$ \\
\hline $\begin{array}{l}1563 \\
1567 \text { (tradução latina } \\
\text { por Clúsio) }\end{array}$ & Garcia de Orta & $\begin{array}{l}\text { «a melhor fruta que há no mundo», } \\
\text { não obstante o «cheiro a cebolas } \\
\text { podres». Sabor de manjar branco, e } \\
\text { «bom para a festa de Vénus». Refe- } \\
\text { re a variedade «cabeça de elefante» } \\
\text { (Malaca) }\end{array}$ & $\begin{array}{l}\text { Informações colhidas em } \\
\text { Goa. Possuiu uma cópia } \\
\text { do fruto, em cera, bem } \\
\text { como uma árvore, que } \\
\text { terá plantado }\end{array}$ \\
\hline $\begin{array}{c}1578 \\
1582 \text { (tradução latina } \\
\text { por Clúsio) }\end{array}$ & Cristóvão da Costa & $\begin{array}{l}\text { Segue Orta, mas descreve o fruto } \\
\text { com maior pormenor, e indica a sua } \\
\text { época. Primeiro esboço do durião } \\
\text { (árvore e fruto). Afirma que a árvore } \\
\text { se chama batan em malaio. (Malaca) }\end{array}$ & $\begin{array}{l}\text { Provável conhecimento } \\
\text { direto (Malaca) }\end{array}$ \\
\hline 1596 & van Linschoten & $\begin{array}{l}\text { Reproduz Costa. } \\
\text { Bela gravura do durião (árvore e } \\
\text { fruto). (Malaca) }\end{array}$ & $\begin{array}{l}\text { Informações colhidas em } \\
\text { Costa. } \\
\text { Poderá ter ouvido falar } \\
\text { do fruto em Goa. }\end{array}$ \\
\hline 1613 & Erédia & $\begin{array}{l}\text { Com um desenho seu do fruto, em } \\
\text { corte. } \\
\text { Parece ter lido Orta. Referência a } \\
\text { uma variedade específica de durião, } \\
\text { o tembaga. }\end{array}$ & $\begin{array}{l}\text { Conhecimento direto } \\
\text { (natural de Malaca) }\end{array}$ \\
\hline 1614 & Diogo do Couto & $\begin{array}{l}\text { «fruta excelente e muito gostosa, } \\
\text { os duriães, os melhores do mundo» } \\
\text { (Amboíno) }\end{array}$ & $\begin{array}{l}\text { Informações obtidas na } \\
\text { Îndia }\end{array}$ \\
\hline
\end{tabular}

«(...) ao derredor há muito boas frutas, assim como uvas que vêm de quatro em quatro meses, e duriões que são da feição de alcachofras e do tamanho de grandes cidras, e de tão singular sabor que diz a gente que naquele pomo pecou Adão.»

Insinua-se aqui, de forma subtil, o efeito afrodisíaco do durião (explicitado por Garcia de Orta, ver abaixo). A descrição que faz confirma que nunca terá visto um durião, que só vagamente se assemelha a uma alcachofra, baseando-se, pois, no que terá ouvido em Goa.

\section{3: João de Barros}

João de Barros, historiador e cronista, que não esteve no Oriente, escreveu sobre os duriões, no segundo volume das Décadas da Ásia (1553):

«(...) duriões, cousa muito estimada e tão gulosa que, contam os mercadores de Malaca, veio àquele porto um mercador com a nau carregada de muita fazenda, e a comeu toda nestes duriões, e gastou em amores das moças malaias.» 
Aparece, de novo, a causalidade entre a ingestão de durião e os «amores», veja-se o discurso de Orta abaixo.

\section{6: Padre Baltasar Dias}

Na Carta aos seus confrades de Portugal (1556), o Padre jesuíta Baltasar Dias descreve Malaca, seis meses após a sua chegada. Diz, a certa altura: « (...) Tem muitas diversidades de frutas, dentro pelos matos, e entre elas uma, a que chamam duriões, a qual, segundo a opinião de todos os que aqui vêm, dizem ser um dos pomos mais suaves, que Deus criou.»

\section{3: Garcia de Orta}

O médico Garcia de Orta (ca. 1501-1568), Figura 3, radicado em Goa, onde morreu, nos seus célebres Colóquios dos simples e drogas e cousas medicinais da Índia e assi dalgumas frutas achadas nela (Goa, 1563) [8], trata do durião no Colóquio Vigésimo («Da datura e dos duriões»), com um complemento no Colóquio Quinquagésimo Oitavo. Ao contrário de Tomé Pires, baseia-se principalmente em relatos, pois o fruto não existia na Índia, nem lá podia chegar em condições de ser comido, «naqueles tempos de viagens demoradas», como observa o Conde de Ficalho [9]. Orta teria de se contentar com uma cópia feita em cera...

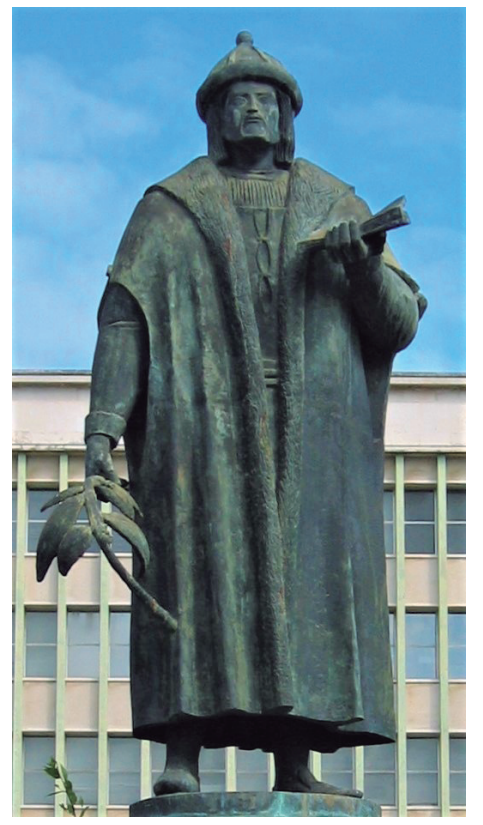

Figura 3 - Representação idealizada de Garcia de Orta com os seus «Colóquios» (estátua da autoria de Martins Correia, em 1958, colocada diante do Instituto de Higiene e Medicina Tropical, Lisboa, quatro séculos após a publicação da obra).

Apresenta assim o durião (pelo seu sabor, mantém-se a grafia original):

\section{«RUANO}

Falando com hum homem, que foy muyto tempo a Malaca, me dixe que a milhor fruta que avia no mundo era huma que chamavam doriões, e lembrovos que tenhamos alguma practica sobre isso.

\section{ORTA}

Eu não a provei, e dos homens que a prováram e as outras frutas nossas, ouvi que sabem bem, e outros dizem o contrairo, scilicet, que nam sabem tam bem como serejas, ou melões pera o gosto; antes me dizem que no principio vos cheiram a çebolas podres, e desque os vindes a gostar, vos sabem muito bem, em tanta maneira, que dizem que um mercador veio a Malaca, e que trazia huma náo carregada de mercadorias, e que vendeo a náo e ellas pera comer, em doriões somente. Isto contáram asi, não sei se he verdade, se mentira; mas em Malaca há muy boas frutas, como uvas e mangas, e as não estimão tanto como doriões. E pera que nam gastemos o tempo muito nisto, vos direi como he o dorião em breves palavras; pois nam he cousa de fisica [Medicina], mais que dizerem os Malaios que he bom pera a festa de Venus [afrodisíaco].

\section{RUANO}

Gabaramme esta fruta tanto que me foi neceçario falarvos nella.

\section{ORTA}

He o dorião um pomo do tamanho de hum melam, e tem huma casca per fóra muyto grosa, e cercada de bicos pequeninos, a modo do que aqui em Goa chamamos jáca, do que ao diante vos farei mençam; he verde per fóra este pomo, e tem apartamentos de dentro, a modo de camaras, e em cada camara tem frutas separadas, na cor e no sabor como manjar branco; e porém não languido, nem que se pegue muyto ás mãos, como o mesmo manjar branco; mas o sabor he muyto gabado de todos, tirando alguns que dizem o que acima dixe; e estas frutas sam do tamanho de hum ovo de galinha pequeno (as que estão no repartimento); algumas ha que não sam brancas, mas como amarelo craro. (...) E tem dentro hum caroço como de pexego, e he redondo.»

No Colóquio Quinquagésimo Oitavo, precisa-se que: (i) há uma variedade muito grande, a que os malaios chamam «cabeça de elefante»; (ii) o fruto «tem dentro, de quatro câmaras para cima (a que eles chamam peitacas [v. Figura 8])»; (iii) «o miolo de dentro he como nata»; (iv) «he muito verde o arvore, e muyto grande e bem copado», sendo a folha «como de uma lança pequena, dividida pelo meio com dois fios, e outros que se tecem para as ilhargas.».

É ainda referida a encomenda de uma réplica do durião, feita em cera, enviada para Cochim numa das «naus de Malaca», e daí transportada para Goa num catur (chalupa). Orta diz, ainda, ter plantado uma árvore do durião, cujo fruto há de provar, «se nos Deus der dias de vida», uma vez que era incerto o número de anos necessário para frutificar (variando de 4 a 40, segundo as fontes [8]).

É notável a coincidência entre a afirmação de Tomé Pires (durião, a melhor fruta do mundo) e a primeira fala de Ruano. Fazendo fé nas várias fontes, seria voz corrente na «Ásia Portuguesa». Orta repete, também, a historieta de João de Barros sobre o mercador dado aos sentidos. O efeito afrodisíaco do durião não se encontra provado, mas é, ainda hoje, objeto de um ditado malaio [4], sendo possível que esta suposta propriedade também contribua para a sua popularidade na Ásia e, em especial, na China. De notar que Orta é o primeiro autor a referir o odor desagradável do fruto (Montanari [10] diz, erradamente, que Orta não fala do odor do durião), bem como a mencionar a semelhança com o sabor do manjar branco.

Em 1567, o botânico Clúsio (Charles L’Écluse, 15261609), que visitara Portugal, e adquirira o livro em Lisboa 
(como refere Ficalho [11] e demonstra Boxer [12]), traduz para latim, com adaptações e cortes, a obra de Orta, e é principalmente nesta versão (em sucessivas edições e traduções para italiano, francês, etc.) que ela se torna conhecida nos meios cultos europeus.

Também em 1567, sai a terceira parte da Crónica do Felicíssimo Rei D. Manuel, de Damião de Góis, onde, a propósito da chegada de Diogo Lopes de Sequeira a Malaca, em 1509, se refere o durião: «Dizem que há nela [Malaca] uma fruta de feição de alcachofras, tamanhos como cidras, a que chamam duriões, que são de tão delicado e suave gosto que muitos homens estrangeiros se deixam ali ficar por respeito desta fruta, ainda que a terra seja doentia.»

O médico espanhol Juan Fragoso (1530-1597), que nunca saiu de Espanha, publica em 1572 os Discursos de las cosas aromaticas, arboles y frutales (...) que se traen de la India Oriental, y sirven al uso de medicina, obra em que reúne as contribuições de Orta sobre o Oriente (sem o citar) e as de um outro pioneiro, o espanhol Monardes (que também não saiu de Espanha), sobre as Américas (igualmente sem o citar). O durião é referido, mas limita-se a condensar a informação dada por Orta.

\section{8: Cristóvão da Costa}

O médico e cirurgião português Cristóvão da Costa (ca. 1538-ca. 1594), Figura 4, que terá estado em Malaca, no seu Tractado de las Drogas, y medicinas de las Indias Orientales (Burgos, 1578), em grande parte baseado na obra de Orta, refere, enquanto «testemunha de vista» (de que se infere, por hipótese, a sua passagem por Malaca), o «saboroso» durião, sublinhando a evolução na perceção do próprio aroma:

«Os homens que nunca o comeram, os primeiros que fazem, lhes parece cheiro de cebolas podres; mas saboreando-os, não comem outra coisa, que melhor lhes cheire ou saiba.»

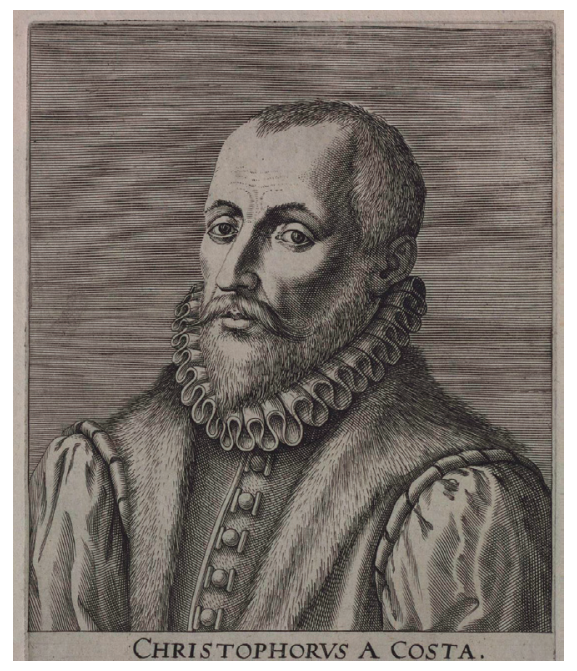

Figura 4 - Cristóvão da Costa (in P. Galle, Imagines L. Doctorum Virorum, Antuérpia, 1587, obra que inclui os retratos de Clúsio e de Damião de Góis).

Menciona ter visto umas oitavas em louvor do durião, mas não considera apropriado incluí-las na obra, quem sabe se pelo teor menos próprio (não esqueçamos que todas as obras passavam pelo crivo da Inquisição).
Cristóvão da Costa precisa o número de compartimentos e de «frutos» (sementes) por compartimento. Indica, ainda, a época do durião, em Malaca, junho a agosto (como ainda hoje) e, até, o seu preço (quatro maravedis). Inclui, também, o primeiro desenho conhecido do mesmo, aliás pouco fidedigno, Figura 5. Também Costa foi traduzido por Clúsio.

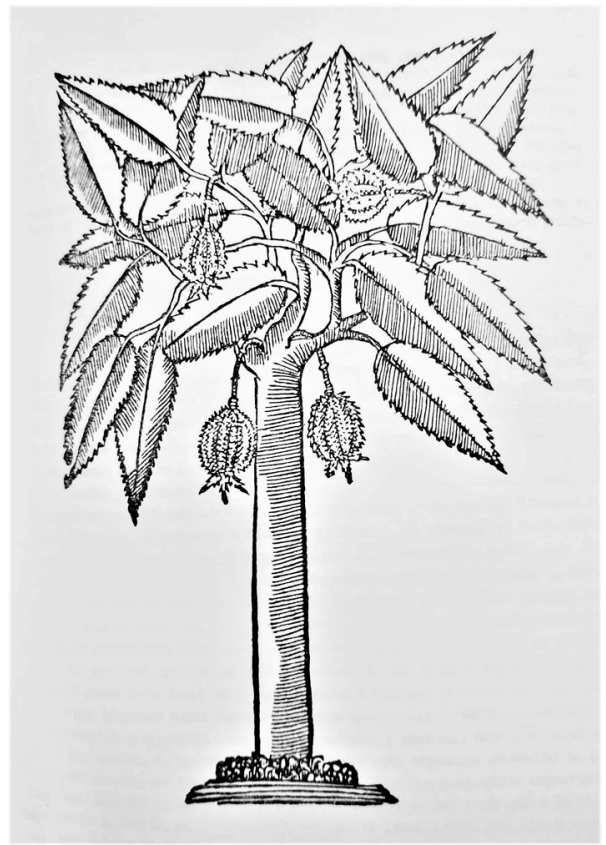

Figura 5 - Esboço da árvore do durião, com os respetivos frutos, tal como a viu Cristóvão da Costa (1578).

O botânico francês Jacques Daléchamps inclui o durião no seu grande tratado Historiae generalis plantarum (Lião, 1586), repetindo as informações de Orta e de Costa, que cita, reproduzindo também o desenho de Costa, com ligeiras alterações mas indicação da origem. O padre espanhol González de Mendoza, em Historia de las cosas mas notables, ritos y costumbres del Gran Reyno de la China (Roma, 1585 e Madrid, 1586), repete que a fruta «es tan buena, que he oydo affirmar a muchos que han dado buelta al mundo que exceden en sabor a todas las que han visto, $\mathrm{y}$ gustado en todo el.». Volta, também, a mencionar Adão, a propósito do durião e de Malaca, tal como figura em Castanheda, mas sem o citar.

\section{6: Jan Huygen van Linschoten}

Como se viu, depois de Orta aparecem várias descrições do durião com pouca ou nenhuma novidade. Foi também o caso do holandês Jan Huygen (ca. 1563-1611), que acrescentou van Linschoten ao seu nome, por razões desconhecidas (a família não tem relação conhecida com a localidade de Linschoten e não usava esse nome). Secretário do Arcebispo de Goa entre 1583 e 1588, adquiriu na Índia Portuguesa um notável conhecimento do Oriente, não só por experiência própria, mas ainda por leituras e contactos, graças a uma posição privilegiada, de que abusou. Demonstra-o na obra publicada após o seu regresso à Holanda, constituída por três livros excelentemente ilustrados, conhecidos coletivamente como Itinerario. Escritos em holandês, foram depressa traduzidos em inglês, alemão 
e latim pois continham mapas, roteiros e muita outra informação portuguesa confidencial. Holandeses e ingleses, espicaçados pela proibição filipina (1594) de entrada dos seus navios mercantes em Lisboa, fizeram bom uso destes livros nas suas primeiras viagens pela Ásia. Por tal razão, a obra de Linschoten era conhecida entre eles por «A chave do Oriente».

No referente ao durião, Linschoten repete o constante nas obras supracitadas, em especial a de Cristóvão da Costa. Apresenta, contudo, uma bela gravura da árvore e dos seus frutos, «que só existem em Malaca», mais fiel ao original do que a de Costa, Figura 6.

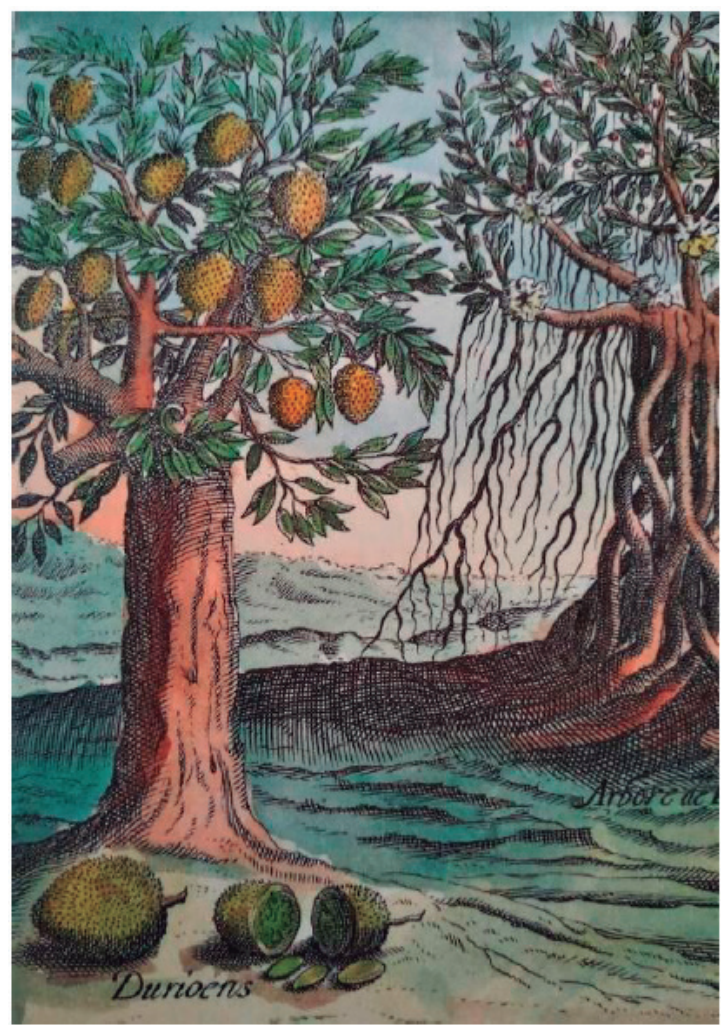

Figura 6 - A árvore do durião e os seus frutos (note-se o nome, em português da época), «considerados os melhores do mundo por quem já os provou». Pormenor da gravura da edição do Itinerário de Linschoten em alemão (De Bry, Francoforte, 1600), que é a imagem no espelho da gravura da edição original de 1596.

Linschoten (e Paludanus, no comentário incluso), seguindo Orta, comparam o sabor do durião com o do manjar branco. Ao contrário de Orta, descrevem esta iguaria, que dizem espanhola (hoje é frequentemente referida como sendo de origem francesa medieval). Não seria, pois, comum na Holanda. Segundo a descrição, o manjar era confecionado com peito de capão, [farinha de] arroz e açúcar rosado [13].

Vários viajantes seiscentistas referem o durião nos seus relatos, casos dos franceses François Martin (de Vitré) (1604) [14] e François Pyrard (de Laval) (1611) [15]. Martin chama-lhe Durion e, embora tenha estado brevemente no norte de Samatra, apresenta uma descrição que não parece resultar de conhecimento direto, mas sim da leitura de Orta e de Costa (autores que cita, a respeito de outro assunto). Pyrard, que esteve em Malaca, talvez fora da época do fruto, segue Martin de muito perto, mas abreviando-o.
Refira-se, ainda, o luso-malaio Godinho de Erédia, único asiático de todos os autores aqui mencionados, e que nunca esteve na Europa.

\section{3: Godinho de Erédia}

Manuel Godinho de Erédia (1563-1623), Figura 7, filho de um fidalgo português e de uma princesa das Celebes, natural da Malaca sob domínio português - que durou 129 anos, terminando em 1641 -, dá notícia pormenorizada do durião, que conhecia bem, na sua obra manuscrita (e pouco divulgada, redescoberta no séc. XIX) Declaração de Malaca e Índia Meridional, com o Cataio (Goa, 1613).

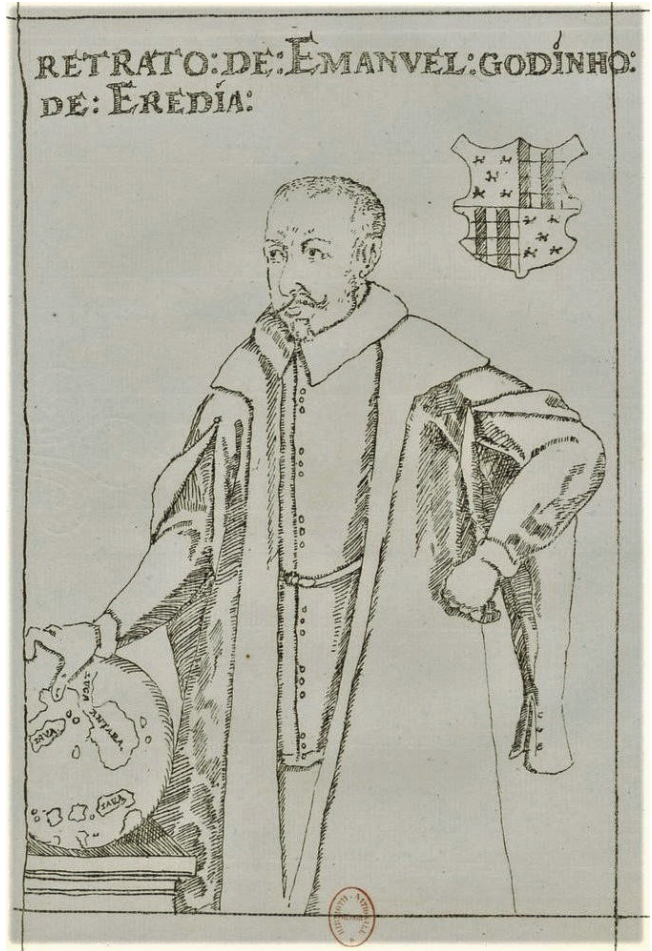

Figura 7 - Autorretrato de Godinho de Erédia (in Declaração de Malaca e Índia Meridional, com o Cataio, Goa, 1613).

Logo na descrição do «sertão de Malaca», diz Erédia:

«E assim o raso como os montes do sertão tudo está coberto de flores e verdes plantas medicinais, e espesso arvoredo (...), além do arvoredo de frutais [árvores de fruto] domésticas e agrestes, porque muitas são muito gostosas e suaves, e diferentes de outras do mundo, como os duriões, fruta semelhante no gosto e sabor ao manjar branco, e quase da mesma massa (...).»

Mais adiante, acrescenta:

«E dos frutais, o durião é árvore grossa e muito alta, e a fruta como cabeça redonda, coberta de bicos piramidais verdes, e, depois de madura, se torna amarela, e a casca toda bicuda, e pela ponta se abre em divisões e peitacas [compartimentos], da maneira da laranja [gomos], e dentro das divisões estão pomos doces muito gostosos como massa de manjar branco, que cobrem o caroço. E desta fruta se acham muitas espécies, e a melhor e mais amanteigada é o Durião Tambaga [16], que me parece a melhor fruta do mundo.»

A descrição é completada com um desenho do fruto (e da folha), feito por si, Figura 8. 
Não deixa de ser curioso verificar que Erédia, natural de Malaca, nasceu no ano da publicação da obra de Orta, em Goa. E é em Goa, onde viveu muitos anos, que Erédia escreve a sua descrição do durião. Malhas que o Império (aliás Estado da Índia) tece...
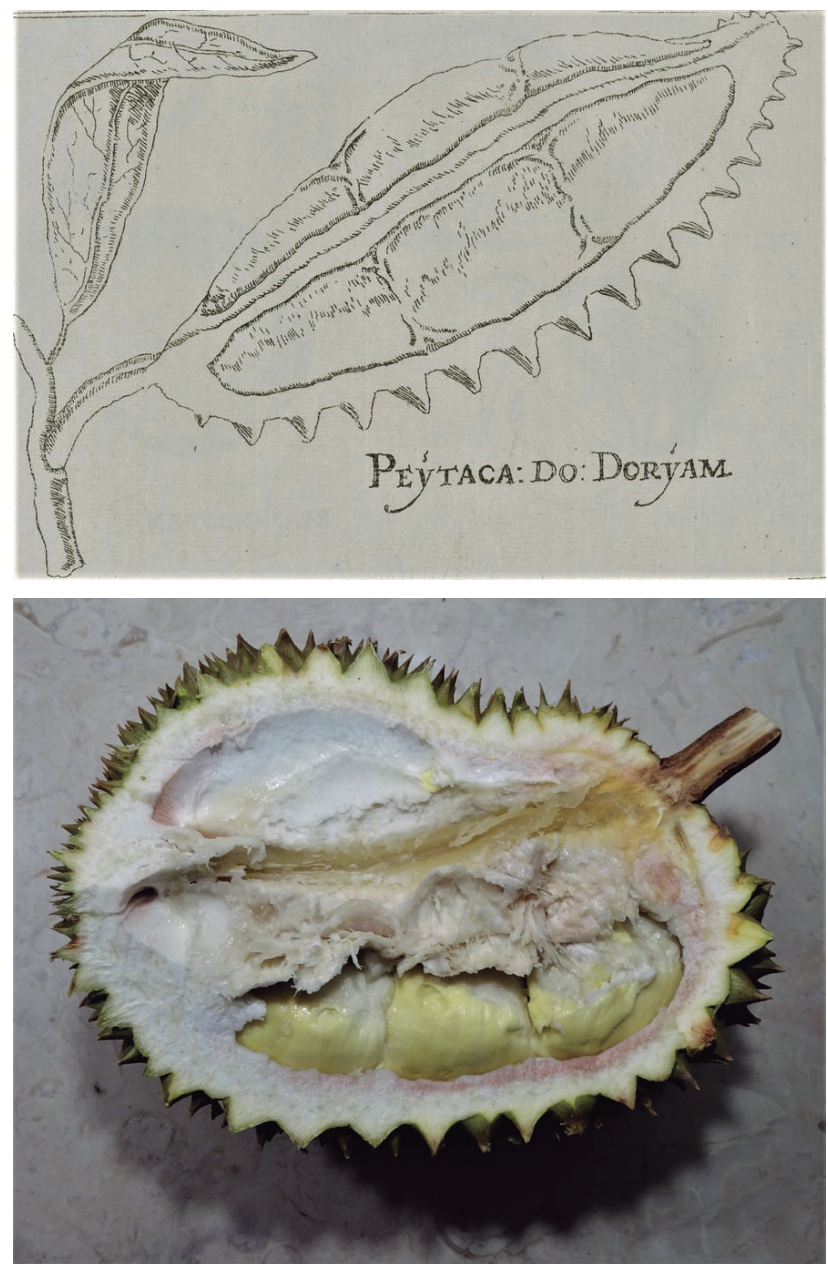

Figura 8 - O durião Tambaga, em corte, desenhado por Erédia (1613, op. cit.), comparado com um fruto atual (clone Mon Thong). Peitaca, termo náutico do sudeste asiático, significa compartimento (de um navio). O termo botânico atual é lóculo. Na fotografia (lóculo inferior), pode ver-se um dos arilos cremosos, alongado e amarelado. No seu interior estão os caroços/ sementes, que fazem lembrar um pouco favas secas, pelo tamanho, forma e dureza. Os arilos correspondem a cerca de 20 a 30\% do peso do fruto, e contêm cerca de 30\% de água, 30\% de glúcidos, 3\% de proteínas e $3 \%$ de lípidos, entre outros constituintes [4].

\section{4: Diogo do Couto}

Diogo do Couto, soldado e historiador, que acabou os seus dias em Goa, já com idade avançada (para a época), menciona, nas Décadas (vol. VIII), a existência de «excelentes e gostosos» duriões em Amboíno (ilha das Molucas, então portuguesa, hoje mais conhecida pelo licor de um outro fruto, o Pisang Ambon - pisang = banana em malaio). Estes duriões só serão objeto de descrição pormenorizada décadas depois, pelo infortunado botânico alemão Rumphius (1627-1702), no Herbarium Amboinense (publicado apenas em 1741), Figura 9.

De todos os autores citados, apenas um punhado - Nicolau Veneto, Tomé Pires, Baltazar Dias, Cristóvão da Costa e Godinho de Erédia - têm «saber de experiência feito», pois viram e provaram o durião, o primeiro em Samatra, os

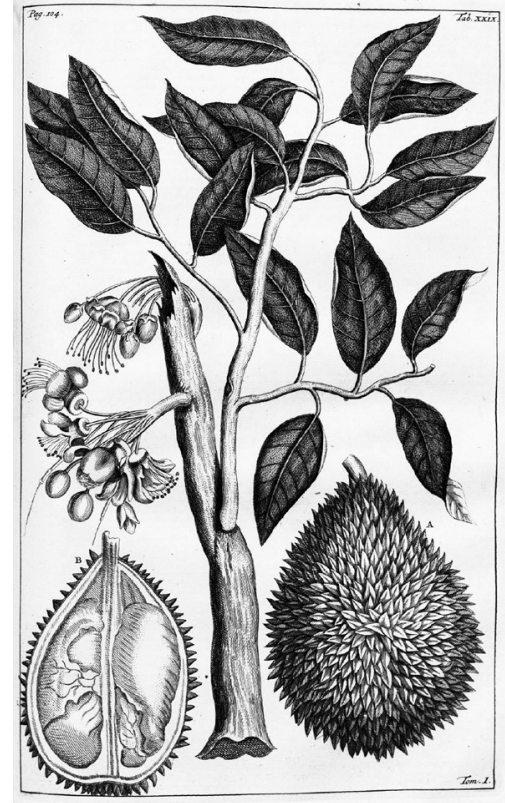

Figura 9 - O durião no Herbarium Amboinense (1741).

restantes em Malaca (no caso de Cristóvão da Costa, trata-se apenas uma probabilidade). Curiosamente, de todos estes, só Cristóvão da Costa se refere ao odor pungente, aliás em termos semelhantes aos de Orta. Tanto este autor como Castanheda descrevem o durião com novidade, mas baseados em contactos e relatos colhidos na Índia (principalmente em Goa). Orta vai, contudo, ao ponto de plantar uma árvore (esperando poder vir a provar dos seus frutos), e de possuir uma cópia, em cera, do durião. João de Barros define a excecionalidade do durião ecoando uma singular e obviamente exagerada história passada em Malaca. Temos, de seguida, os autores não portugueses que, nas suas compilações, repetem, noutras línguas, o que leram ou ouviram dos portugueses, casos de Clúsio, Fragoso, Daléchamps, Mendoza e Linschoten. Os franceses Martin e Pyrard, que estiveram em Samatra e Malaca, respetivamente, já no início de seiscentos, portanto praticamente um século depois dos portugueses aí terem chegado, não dão informação nova nem se depreende do que escrevem que tenham, sequer, visto o fruto. Só muito mais tarde, com Rumphius, voltamos a ter informação em primeira mão, agora sobre o durião de Amboíno, primeiro assinalado por Couto. Finalmente, numa última categoria, estão os numerosos autores que apenas repetem ou traduzem os precedentes.

Da compilação aqui apresentada, é forçoso concluir que os contributos de Orta e de Costa são os mais significativos, e os que mais influência tiveram no conhecimento do durião pela Europa culta quinhentista e seiscentista.

Infelizmente, Orta é citado no já referido Hobson-Jobson [3] apenas num ponto marginal, e Wallace [2] só menciona Linschoten (e Paludanus), autores tardios que, como se viu, repetem Orta e Costa. Brown [4], que ignora o Hobson-Jobson, refere Orta, mas de forma duplamente errada, evidenciando que não o leu, e dando, além disso, destaque ao plagiador [17] Fragoso, que passa por pioneiro. Já a entrada do durião na Wikipedia, embora incompleta, inclui o contributo de Orta.

A evolução da atitude dos europeus em relação ao durião é discutida no Hobson-Jobson [3] (sécs. XVII a XIX) e 
desenvolvida no interessante, mas algo discutível, artigo de Montanari [10]. Também Alfredo Margarido se interroga sobre a limitada aceitação do durião no Ocidente [18,19].

\section{9: Camilo Pessanha}

Neste contexto, é muito interessante o relato que o poeta Camilo de Almeida Pessanha (1867-1926) faz do seu contacto com o durião, em 1909 [20]. Ao regressar a Macau (onde se estabelecera em 1894), após uma das suas viagens à Metrópole, Pessanha faz escala em Singapura, onde muda de um navio holandês para um navio inglês:

«Finalmente, em Singapura, encontrei-me com os padres da missão portuguesa [Figura 10], que além de, pelo conhecimento que têm daquele meio, me facilitarem enormemente os trabalhos, bastante complicados, do transbordo, me trouxeram de passeio pela cidade, em um carro que têm particular, e me deram um ótimo jantar de peixe e de frutos da região, alguns dos quais se não encontram em nenhum outro ponto do mundo. Havia entre esses frutos um, principalmente, que eu tinha grande desejo de conhecer - o durião. É celebrado pelo seu gosto delicioso e pelo seu cheiro abominável. Quem se habituou a ele diz que o fica amando como um vício, irresistível. Efetivamente deve ser assim, tão completo é o sabor, em que o paladar, por muito tempo que se tenha na boca, vai descobrindo sempre delícias novas. O cheiro, forte, quando se abre o fruto, surpreende com um cheiro característico, de sentina, mas também pouco a pouco se vai descobrindo que é um perfume, composto de muitos perfumes...»

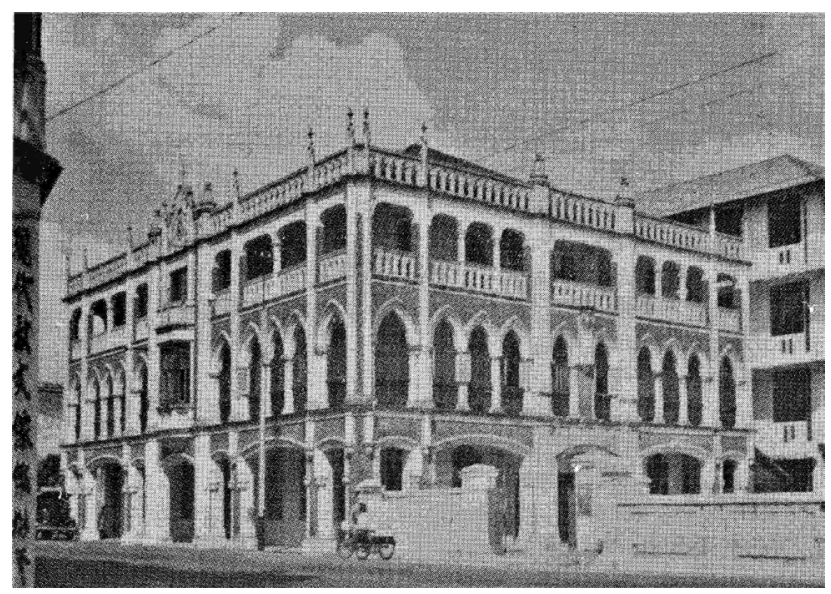

Figura 10 - A missão portuguesa em Singapura (143 Victoria St.) nos anos 1950. Entre finais do séc. XIX e meados do séc. XX, foi ponto de acolhimento dos portugueses que viajavam de/para Macau ou Timor em funções oficiais (in M. Teixeira, The Portuguese Missions in Malacca and Singapore, Vol. III, Agência Geral do Ultramar, Lisboa, 1961).

\section{Durião ou duriões?}

Durião vem do malaio duri, espinho [3]. A árvore do durião, Figura 11, será o durieiro, mas parece tratar-se de um neologismo. Existem cerca de 30 espécies do género Durio, sendo a mais comum o D. zibethinus (Lineu, 1774) [4]. Uma outra espécie, o D. dulcis, tem frutos igualmente comestíveis, mas ainda mais fedorentos do que o durião comum, fazendo-se por isso notar a grande distância [4]. O fruto não

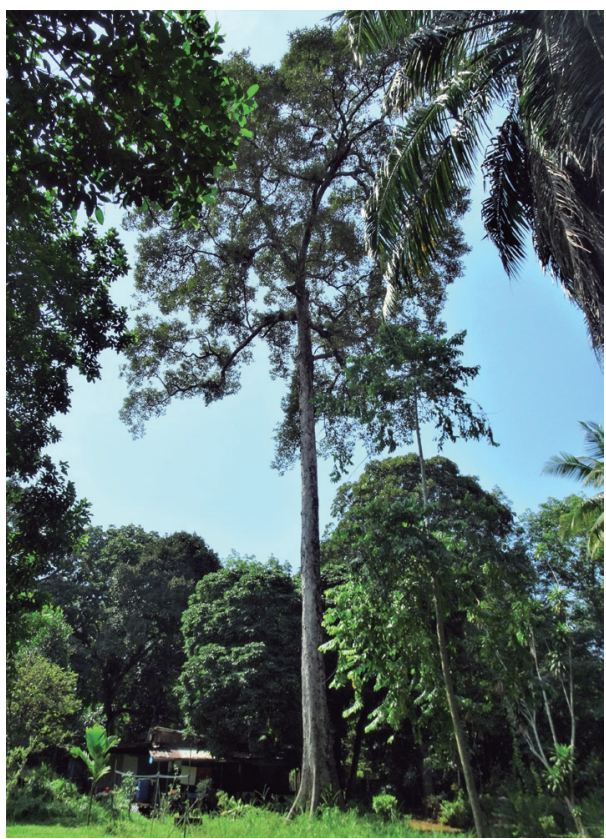

Figura 11 - A árvore do durião (Kampong Durian, Pulau Ubin, Singapura). Pode atingir algumas dezenas de metros de altura, o que torna muito perigoso passar sob a sua ramagem quando está carregada de frutos maduros. As árvores de cultivo são muito mais pequenas. As únicas árvores do durião que se conhecem em Portugal encontram-se, muito apropriadamente, no Jardim Garcia de Orta (talhão de Goa), no Parque das Nações, em Lisboa, tendo sido plantadas por alturas da Expo 98.

é colhido, mas sim apanhado do chão, ou amparado na queda (por uma rede ou um cabo que o impedem de bater no chão, quando se desprende naturalmente do ramo).

O nome da espécie vem do uso tradicional do fruto, na ilha de Amboíno, para atrair gatos almiscarados, também chamados civetas ou zibetas [21]. A árvore, cujas flores esbranquiçadas abrem de noite, é principalmente polinizada por morcegos [4].

Há várias centenas de tipos específicos de durião (variedades ou clones), cada um com o seu aspeto, consistência e sabor específico, do amargo ao doce. Os clones são designados por um nome e pelo código de registo Dn, iniciado pelo Departamento de Agricultura da Malásia em 1934 (presentemente há mais de 200 clones registados). Um dos mais comuns e apreciados na Malásia e em Singapura é o Musang King («Civeta Rei», ou Cat Mountain King, D197, registado em 1993), Figura 12. Outras variedades são o Red Prawn («Gamba Vermelha», pela sua cor, D175), Figura 12, o Sultan (D24), e o Tembaga («Cobre», D118), provavelmente relacionado com a variedade descrita por Erédia [16]. A variedade tailandesa que domina as exportações é o Mon Thong («Almofada Dourada», D159, ver Figuras 2 e 8), pela doçura, menor odor e longa duração (cerca de 20 dias - na maioria dos casos o fruto só é comestível até quatro dias depois da queda) [22]. Do «cabeça de elefante» mencionado por Orta não parece ter ficado traço, pelo menos em termos de designação. Há alguns anos, foram obtidas variedades sem cheiro desagradável, mas não pegaram.

Para além do durião ao natural, existem inúmeros produtos alimentares derivados, tais como doces, gelados, Figura 13, e até piza e café! 


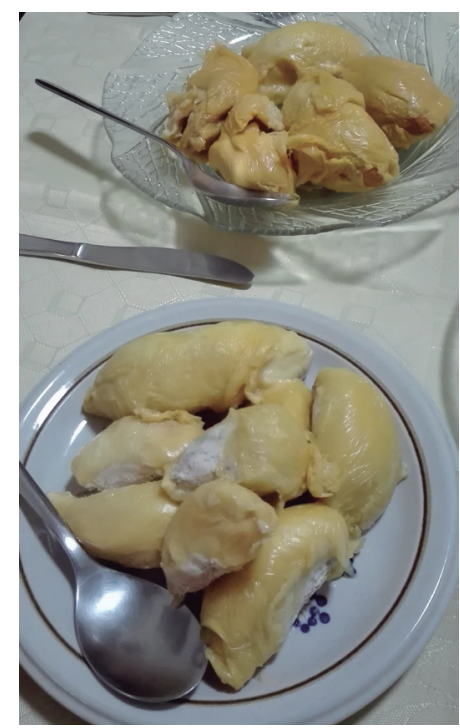

Figura 12 - A polpa (arilo) do durião, variedades Red Prawn e Musang King.
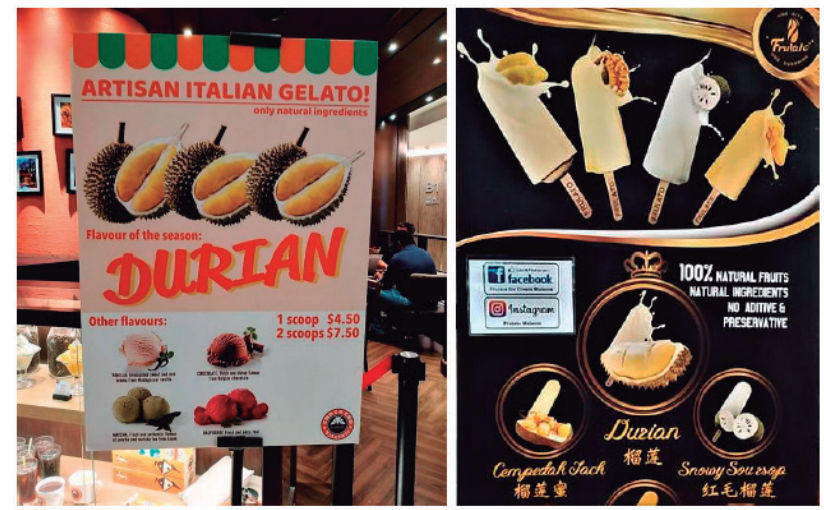

Figura 13 - Gelados de durião, artesanais (Singapura), deliciosos pelo sabor e pela consistência, e industriais (Malaca).

\section{Odor e paladar do durião}

Sabe-se, há mais de um século, que o odor do durião resulta, de forma dominante, mas não exclusiva (pois também existem notas frutadas), de compostos voláteis contendo enxofre [4]. Recorde-se, a este propósito, o cheiro a cebola podre mencionado por Orta e Cristóvão da Costa. Posteriormente, foi proposto que o odor provinha de sulfuretos e tióis (cheiro a cebola podre) e de ésteres (aroma frutado), dependendo a importância relativa dos sulfuretos e dos tióis do clone [4]. Outros autores sugeriram a presença de indole e derivados (escatole), compostos associados ao cheiro das fezes [4] (recordar agora a descrição feita por Camilo Pessanha).

A análise química da polpa de duriões maduros revelou diferenças significativas entre clones, mas sempre com a componente sulfurosa, não se confirmando a presença dos indoles [4].

Em 1972, foram identificadas várias dezenas de compostos voláteis, sulfurosos e ésteres, que, em conjunto, produzem os odores conhecidos [23]. Os contribuintes sulfurosos incluíam metanotiol, etanotiol e propano-1-tiol, bem como os sulfuretos de dimetilo e de dietilo, para além de $\mathrm{H}_{2} \mathrm{~S}$ e de alguns dissulfuretos e trissulfuretos voláteis. A componente sulfurosa foi atribuída, principalmente, ao propano-1-tiol, enquanto que a frutada foi atribuída, principalmente, ao 2-metilbutanoato de etilo (Figura 14) [23].<smiles>CCOC(=O)[C@H](C)CC</smiles>

Figura 14 - As duas principais moléculas responsáveis pelo odor do durião Mon Thong, 1-(etilsulfanil)etano-1-tiol (cheiro sulfuroso) e (2S)-2-metilbutanoato de etilo (aroma frutado) [25].

Os compostos voláteis de enxofre provêm da biotransformação dos aminoácidos metionina e cisteína, na fase de amadurecimento do fruto [24].

De referir que o etanotiol é adicionado em pequeníssima proporção ao gás natural (e a outros gases combustíveis inodoros) para alertar, de forma simples e imediata, para a existência de fugas, produzindo o familiar «cheiro a gás».

Só recentemente [25] foi possível estabelecer que a combinação de apenas dois compostos, em concentrações apropriadas, permite reproduzir o cheiro do durião (pelo menos para o clone Mon Thong). São estes o referido (2S)-2-metilbutanoato de etilo, enquanto que o composto de enxofre é o 1-(etilsulfanil)etano-1-tiol (Figura 14).

O paladar, muito agradável e complexo, do durião, ainda não se encontra elucidado do ponto de vista químico, sabendo-se, contudo, que os ácidos málico e cítrico são os principais responsáveis pelo sabor ácido [24].

O genoma do durião (clone Musang King) foi determinado recentemente [26]. Os autores do estudo propõem que o odor intenso associado à fase de amadurecimento do fruto teria vantagens na propagação da espécie (transporte das sementes a longa distância), atraindo primatas sensíveis ao cheiro e não espécies de menor dimensão orientadas apenas pelo sistema visual.

\section{Conclusões}

O durião é um fruto paradoxal, pois tem um sabor e consistência deliciosos, mas um cheiro usualmente considerado fétido por quem contacta com ele pela primeira vez. Este odor, com componentes fétida e frutada, está associado, respetivamente, a compostos voláteis de enxofre e a ésteres (entre outros).

Existe, contudo, um processo de habituação que diminui ou mesmo inverte a resposta ao cheiro do durião, que passa de repelente a neutro ou, até, a agradável, como confirma o autor deste artigo. A habituação ao cheiro é, aliás, algo que os químicos conhecem bem, designadamente em relação a muitos dos solventes que usam.

A primeira referência a esta habituação, no caso do durião, é devida a Garcia de Orta (1563), a que se seguiu Cristóvão da Costa (1578). Contudo, na literatura de língua inglesa, cita-se Wallace, que escreveu três séculos depois (!). Por sua vez, este naturalista também só refere, para além da sua experiência pessoal, o livro de Linschoten (1596), neste e noutros pontos decalcado dos de Orta e Costa.

Fica ainda por desvendar a relação entre a composição química e o paladar excelente.

Ao contrário de outros frutos exóticos que se tornaram populares nas últimas décadas, a difusão do durião no Ocidente continua muito limitada, e está praticamente restrita 
a algumas comunidades asiáticas (sudeste asiático e China). Em Portugal, a situação é tanto mais curiosa, porquanto os portugueses foram não só os primeiros europeus a apreciá-lo e a comê-lo regularmente (principalmente em Malaca, mas também em Samatra, Java, Celebes e Molucas), e também a descrevê-lo em pormenor, destacando as suas características singulares, mas ainda os principais responsáveis, na Europa, por este conhecimento.

\section{Agradecimentos}

Aos amigos de Singapura, que me deram a provar, pela primeira vez, o durião; ao Dr. Vasco Bonifácio, pelos produtos alimentares contendo durião que trouxe de uma viagem ao sudeste asiático, para degustação pelo Grupo 3 do CQFM; ao Prof. Manuel Prieto, pelo seu interesse e apoio na investigação, que culminou numa frutuosa deslocação conjunta ao MARL.

\section{Notas e referências}

[1] No principal e mais antigo relato das viagens das esquadras do famoso almirante eunuco Zheng He, chinês e muçulmano (1371-1435, também dito Cheng Ho, em que Ho é o nome próprio e Cheng o apelido, nomes atribuídos pelo Imperador), efetuadas entre 1405 e 1433, assinala-se a existência do durião no norte da ilha de Samatra [27]. Neste roteiro, escrito por Ma Huan, e datado de 1433, mas provavelmente publicado apenas em 1451 [27], afirma-se: «Existe [em Samudera, reino do norte de Samatra] um fruto mal-cheiroso, chamado tu-erh-wu [ou tu-erh-yen] , (...) coberto de saliências aguçadas. Quando está maduro, divide-se em cinco ou seis secções. Cheira a carne podre. No interior há catorze ou quinze porções carnudas, do tamanho de castanhas, e cor branco-amarelado, muito doces e deliciosas. No interior dessas porções existem sementes que, torradas, sabem a castanha.» Até ao início do séc. XX, os referidos relatos eram muito pouco conhecidos na China, e totalmente desconhecidos na Europa. A passagem dos navios chineses pela costa oriental de África e pela Índia deixou memórias duradouras nos locais, tendo sido referida aos portugueses logo na primeira viagem de Vasco da Gama, que se deu cerca de setenta anos depois. Nessa altura, os juncos chineses já não iam além de Malaca. Os feitos de Zheng He, embora notáveis, e de grande impacto político na região, têm sido empolados, designadamente quanto à novidade das navegações (as rotas do Mar da China e do Índico eram conhecidas há séculos, e sulcadas com frequência por marinheiros de várias proveniências), ao tamanho dos navios e ao caráter pacífico das viagens, veja-se, por exemplo, Zheng He, Images \& perceptions, C. Salmon and R. Ptak eds., Harrassowitz Verlag, Wiesbaden, 2005.

[2] A. R. Wallace, The Malay Archipelago: The Land of the Orang-Utan and of the Bird of Paradise, Mcmillan, London, 1869.

[3] H. Yule, A. C. Burnell, Hobson-Jobson: A glossary of colloquial Anglo-Indian words and phrases, and of kindred terms, etymological, historical, geographical and discursive, Crooke, London, 1886.

[4] M.J. Brown, Durio - A bibliographic review, IPGRI, New Delhi, 1997.

[5] O relato da viagem foi compilado e vertido para latim pelo humanista Poggio Bracciolini, secretário de vários papas.
O livro que contém este relato (entre outros assuntos), foi impresso em Itália em 1492. Houve logo edição portuguesa em 1502: O livro de Nicolau Veneto, traduzido e publicado pelo impressor alemão Valentim Fernandes (radicado em Portugal e natural da Morávia, hoje na Chéquia), em complemento a O Livro de Marco Polo, e ainda com um outro relato de viagem recente pelo Oriente, a Carta do genovês Jerónimo de Santo Estevão. Curiosamente, foi a versão portuguesa que serviu de base para a edição em italiano, devida a Giovanni Ramusio, no primeiro volume da coletânea Navigationi et Viaggi (Veneza, 1550).

[6] G. Bouchon, A.-L. Amilhat-Szary, ed., Le voyage aux Indes de Nicolò de' Conti (1414-1439), Chandeigne, Paris, 2004.

[7] Veio a morrer na China, na sequência de uma embaixada falhada ao Império do Meio, em parte precisamente por causa da conquista de Malaca, cujo sultão deposto, vassalo do imperador chinês desde as viagens de Zheng He, se tinha queixado a este da "malfeitoria".

[8] A última parte do título, talvez por mais comezinha, é sistematicamente omitida, mas traduz parte do conteúdo, e faz especial sentido neste trabalho.

[9] Responsável pela terceira edição dos Colóquios (1891-2), ainda hoje de referência, e autor de uma notável biografia de Garcia de Orta [11], elaborada a partir dos dados disponíveis à época. Por curiosidade, refira-se que Ficalho dá como exemplo do pouco cuidado da segunda edição (1872), a identificação do durião com uma espécie de anona (depois corrigida em errata).

[10] A. Montanari, The stinky king: western attitudes toward the durian in colonial Southeast Asia, Food, Culture \& Society 20 (2017) 395-414.

[11] Conde de Ficalho, Garcia da Orta e o seu tempo, Imprensa Nacional, Lisboa, 1886.

[12] C.R. Boxer, Two pioneers of Tropical Medicine: Garcia d'Orta and Nicolás Monardes, Wellcome, London, 1963.

[13] Para uma receita portuguesa da mesma época, veja-se Domingos Rodrigues, Arte de Cozinha, $2^{\mathrm{a}}$ ed., João Galrão, Lisboa, 1683, p. 131.

[14] F.M. de Vitré, Description du premier voyage faict aux Indes orientales par les françois en l'an 1603, L. Sonnius, Paris, 1604.

[15] F.P. de Laval, Discours du voyage des François aux Indes orientales, Le Clerc, Paris, 1611.

[16] Tambaga ou tembaga significa «cobre» em malaio. Trata-se de uma variedade de durião ainda hoje existente (provavelmente com diferenças) e apreciada.

[17] J.L.F. Febrer, Juan Fragoso y los discursos de cosas aromáticas, árboles y frutales... (1572), Universitat de València, 2001.

[18] A. Margarido, As surpresas da flora no tempo dos Descobrimentos, Elo, Lisboa, 1994.

[19] A. Margarido, Plantas e conhecimento do mundo nos séculos XV e XVI, Alfa, Lisboa, 1989.

[20] A. Quadros (org.), Obras de Camilo Pessanha, vol. 2, Pub. Europa-América Mem Martins, 1988, pp. 98-99.

[21] As bagas de café, depois de digeridas e excretadas por estes gatos, ficam com um sabor especial, devido às enzimas digestivas dos mesmos, e são usadas para fazer um café dispendioso e muito apreciado na região, o Kopi Luwak (café de civeta), mas cuja origem o torna repulsivo para os não aculturados. 
[22] W. Tantrakonnsab, N. Tantrakoonsab, Thai export of durian to China, in Impact of China's increasing demand for agro produce on agricultural production in the Mekong Region, JETRO, Bangkok, 2018.

[23] J. Baldry, J. Dougan, G.E. Howard, Phytochemistry 11 (1972) 2081-2084.

[24] P. Pinsorn, A. Oikawa, M. Watanabe, R. Sasaki, P. Ngamchuachit, R. Hoefgen, K. Saito, S. Sirikantaramas, Food Chemistry 268 (2018) 118-125.
[25] J.-X. Li, P. Schieberle, M. Steinhaus, J. Agric. Food Chem. 65 (2017) 639-647.

[26] B.T. Teh, K. Lim, C.H. Yong, C.C.Y. Ng, S.R. Rao, V. Rajasegaran, W.K. Lim, C.K. Ong, K. Chan, V.K.Y. Cheng, P.S. Soh, S. Swarup, S.G. Rozen, N. Nagarajan, P. Tan, $\mathrm{Na-}$ ture Genetics 49 (2017) 1633-1641.

[27] M. Huan, Ying-yai Sheng-lan (The overall survey of the ocean's shores) [1433], J. V. G. Mills ed., Hakluyt Society, London, 1970.

\section{Atualidades Científicas}

\section{"Neve" de polietilenimina para captura eficiente de $\mathrm{CO}_{2}$}

A problemática da redução das emissões de $\mathrm{CO}_{2}$ tem sido objeto de intenso debate e pesquisa científica. A captura do $\mathrm{CO}_{2}$, produzido em larga escala por fontes industriais, pode assumir um papel importante na diminuição das emissões de $\mathrm{CO}_{2}$ para a atmosfera. Até à data, a "lavagem com aminas” é a principal técnica usada na indústria para a captação de $\mathrm{CO}_{2}$ devido à sua alta reatividade, alta seletividade e custo relativamente baixo. No entanto, esta técnica possui alguns problemas, incluindo uma eficiência de absorção reduzida, perda da amina volátil, corrosão, e preocupações ambientais e de saúde. Assim, processos alternativos continuam a ser procurados com este fim. Uma das abordagens mais promissoras, e que tem atraído uma atenção crescente nos últimos anos, tem sido o dos adsorventes sólidos funcionalizados com aminas. Estes adsorventes são tipicamente preparados por impregnação ou grafting de aminas na superfície dos poros de suportes altamente porosos, tais como carvão ativado, sílica gel, e várias nanopartículas. Por exemplo, um dos estudos mais antigos envolve o uso de MCM-41 contendo polietilenimina (PEI). Desde então, os adsorventes sólidos funcionalizados com PEI têm sido extensivamente investigados por diferentes grupos. No entanto, estes adsorventes são muitas vezes difíceis de sintetizar, podem perder algumas das unidades de PEI por lixiviação e não absorvem $\mathrm{CO}_{2}$ de uma forma muito eficiente.

Xingguang Xu, da Commonwealth Scientific Industrial Research Organisation (CSIRO), em Perth, Austrália, e colegas desenvolveram uma nova forma de PEI que é fácil de sintetizar, não precisa de um suporte sólido, e tem um elevado desempenho na captação de $\mathrm{CO}_{2}$. A equipa preparou um gel fazendo reagir PEI com buta-1,3-dieno diepóxido (BDDE) que, após pulverização, originou uma espécie de "neve” seca de PEI. A preparação do adsorvente demora apenas 15 minutos e a captação de $\mathrm{CO}_{2}$ é a mais elevada relatada até ao momento para materiais funcionalizados com PEI. De acordo com os investigadores, a "neve” de PEI pode ser uma plataforma promissora para a captura de $\mathrm{CO}_{2}$ no futuro.

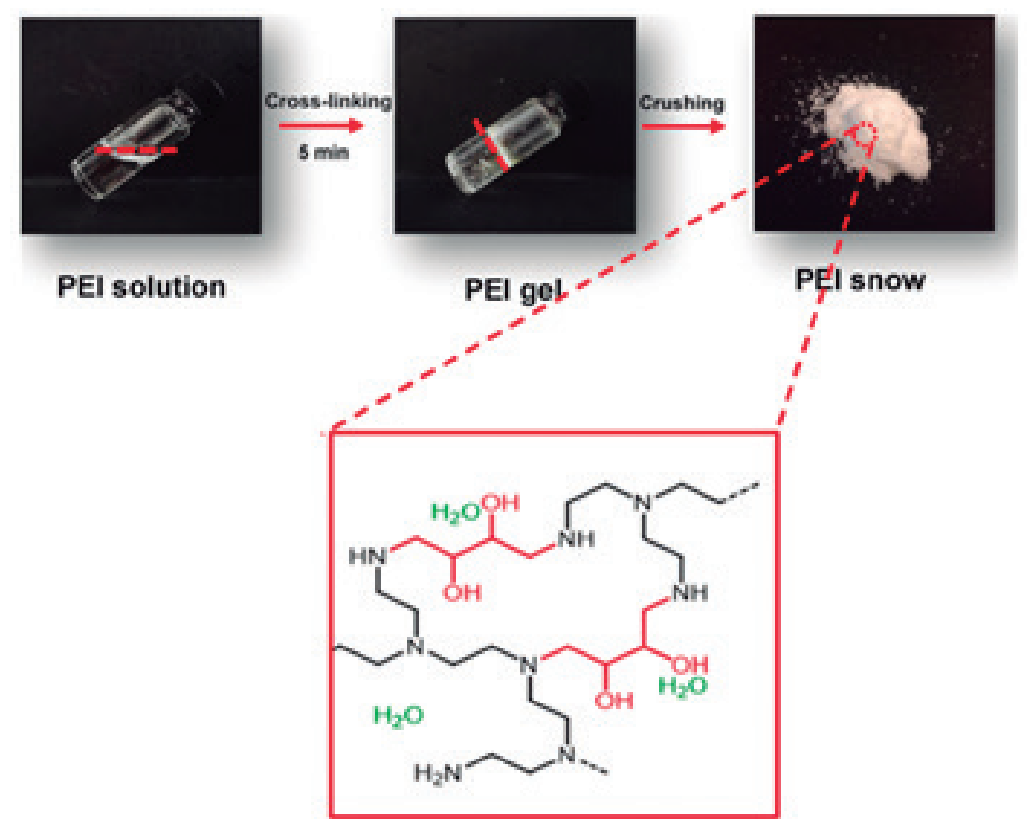

\section{Fonte:}

Polymer "snow" captures carbon dioxide, https://www.chemistryviews. org/details/news/11171467/Polymer_ Snow_Captures_Carbon_Dioxide. html (Acedido em 11/08/2019)

X. Xu, B. Pejcic, C. Heath, M. B. Myers, C. Doherty, Y. Gozukara, C.D. Wood, ACS Appl. Mater. Interfaces 11 (2019) 26770-26780.

Paulo Mendes (pjgm@uevora.pt) 